Article

\title{
The Influence of Emotional Intelligence and Cultural Adaptability on Cross-Cultural Adjustment and Performance with the Mediating Effect of Cross-Cultural Competence: A Study of Expatriates in Taiwan
}

\author{
Ying Kai Liao ${ }^{1}$, Wann-Yih Wu ${ }^{1}$, Tuan Cong Dao ${ }^{2,3, *}$ and Thi-Minh Ngoc Luu ${ }^{4}$ \\ 1 Program of International Business, Nanhua University, Chiayi County 62249, Taiwan; \\ yksuper889@nhu.edu.tw (Y.K.L.); wanyi@nhu.edu.tw (W.-Y.W.) \\ 2 Department of Business Administration, Nanhua University, Chiayi County 62249, Taiwan \\ 3 Department of Organization and Personnel, Vietnam National University, \\ Hanoi 10000, Vietnam \\ 4 School of Business Administration, University of Economics and Business, \\ Vietnam National University, Hanoi 10000, Vietnam; 1tmngoc@vnu.edu.vn \\ * Correspondence: daotuan.vnu@gmail.com
}

Citation: Liao, Y.K; Wu, W.Y.; Dao, T.C.; Ngoc Luu, T.-M. The Influence of Emotional Intelligence and Cultural Adaptability on CrossCultural Adjustment and Performance with the Mediating Effect of Cross-Cultural

Competence: A Study of Expatriates in Taiwan. Sustainability 2021, 13, 3374. https://doi.org/10.3390/su 13063374

Received: 11 January 2021

Accepted: 10 March 2021

Published: 18 March 2021

Publisher's Note: MDPI stays neutral with regard to jurisdictional claims in published maps and institutional affiliations.

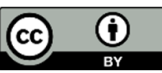

Copyright: $@ 2021$ by the authors. Licensee MDPI, Basel, Switzerland. This article is an open access article distributed under the terms and conditions of the Creative Commons Attribution (CC BY) license (http://creativecommons.org/licenses/by/4.0/).

\begin{abstract}
This study examines the influence of antecedents on cross-cultural competence and crosscultural adjustment as well as the mediating role of cross-cultural competence for the influence of cultural adaptability on cross-cultural adjustment and expatriate performance. The partial least squares structural equation modeling technique was adopted to analyze the data from a survey of 240 expatriates working in Taiwan. The results confirm the positive effect of emotional intelligence and cultural adaptability on cross-cultural competence and of emotional intelligence and cross-cultural competence on cross-cultural adjustment. Moreover, the findings reveal a highly valuable milestone insight into the role of cross-cultural competence regarding their competency to foster the indirect influence of cultural adaptability on cross-cultural adjustment and expatriate performance in culturally diverse settings. Given that previous research has rarely identified the mediating role of cross-cultural competence in improving cross-cultural adjustment and expatriate performance, these findings could be highly beneficial for academics to conduct further validation and professional human resource managers in recruiting and managing expatriates.
\end{abstract}

Keywords: emotional intelligence; cultural adaptability; cross-cultural competence; cross-cultural adjustment; expatriate performance

\section{Introduction}

The trend of globalization and the foundation of a borderless economy have generated imperative demands and requirements for individuals concerning their ability to work not only at local businesses but also at multinational corporations. The hiring or sending of expatriates for employment overseas is always a matter of concern and a top priority for both practitioners and researchers. Proceeding from the need to find new partners and customers, firms have to expand production and business activities in different areas to achieve profit targets. In 2016, a major investigation in a special report by hrmagazine.co.uk indicated that global mobility assignments have increased by $25 \%$ in the past decade - and it predicted a further 50\% growth in international assignments by 2020 [1]. According to Ariss and Henry [2], 96 million is the number of individuals that is forecasted to move from developing countries to more developed countries for the period 2010-2050. Approximately 80\% of mid-size and large enterprises are currently sending 
professionals abroad, and the remainders are planning to increase the number of expatriates and overseas missions [3]. Consequently, cross-cultural competence plays an important role in enhancing the success of expatriates who have a crucial influence on the sustainable development of the organization as well as the success of international business missions [4-6].

However, it has been reported that most of these expatriates initially have difficulty in conducting themselves correctly and efficiently in the new culture when they are sent overseas [7]. Hofstede [8] argued that individuals' cultural values can be measured by power distance, uncertainty avoidance, individualism, masculinity, and long-term orientation. People in different countries may perceive cultural values differently, which may result in diverse ways of thinking and behaving [9]. Business communications and interactions between expatriates and host country employees often fail due to cultural differences and a shortage of core competence to handle such differences. Takeuchi et al. [10] indicated that one of the most common explanations by foreigners for terminating expatriate missions earlier than planned is poor adjustment and performance. Therefore, in order to improve expatriate's cross-cultural adjustment and performance, cultural differences and specific host-country national values and standards maintain crucial features that should not be ignored by expatriates [11].

Taiwan is considered an attractive place for foreign direct investment because its economy benefits from regional economic vitality, it is a destination with high expenditure capacity, and it accords eminence to the high-tech industry. Taiwan has built up one of the most developed high-tech markets worldwide due to its advanced products, availability of resources and assets, and specialized human capital resources. Many Taiwanesebased high-tech companies have become the largest global suppliers of computer chips, semiconductors, personal computers, monitors, accessories, and circuit boards [12]. In addition, Taiwanese culture is a mixture of Confucian Chinese and indigenous Taiwanese cultures. Prior scholars have identified some significant differences between Taiwanese culture, Chinese culture, and Western cultures $[9,13,14]$. Regarding expatriates facing intercultural issues in their daily lives and their jobs, Taiwan provides a good environment for implementing the investigation about factors that can influence expatriate's success.

The research literature has demonstrated that cross-cultural competence has been considered as emerging attention over the last ten years [4,15]. Both scholars and managers in the field of international business have emphasized that cross-cultural competence is an essential ability to avoid those failures in multinational corporations [4]. It is indicated that when expatriates lack cross-cultural competence, they cannot adjust to the new environment and achieve the targets and goals of their assignments [15]. These problems lead to uncertain feelings, personal and professional stress, frustration, and confusion, along with causing differences in behavioral expectations and performance [16,17]. Accordingly, prior researchers paid increased attention to the exploration of potential aspects and antecedents of expatriate cross-cultural competence such as Bartel-Radic and Giannelloni [4], Johnson et al. [18], Li [5], Wang et al. [15], and Wu and Bodigeler-Koehler [19]. Additionally, they emphasized that the characteristics of cross-cultural competence are highly complicated and there is a need for more studies to comprehend the definition and enhance its measurement. Moreover, they called for future studies to investigate a deeper understanding of the true characteristics, role, and outcomes of cross-cultural competence. However, no previous study has identified the mediating role of cross-cultural competence in promoting expatriate's cross-cultural adjustment and expatriate performance. Therefore, this study focus on implementing the four-fold following objectives:

(1) To identify the influence of emotional intelligence and cultural adaptability on crosscultural competence and cross-cultural adjustment;

(2) To identify the influence of cross-cultural adjustment on expatriate performance;

(3) To identify the mediating effect of cross-cultural competence for the influences of cultural adaptability on cross-cultural adjustment; 
(4) To identify the mediating effect of cross-cultural competence for the influences of cultural adaptability on expatriate performance.

\section{Literature Review and Hypothesis Development}

\subsection{Emotional Intelligence}

According to Altinay et al. [20], emotional intelligence has been defined in various approaches ranging from problem-solving, by virtue of thoughts, feelings, and intuition [21], to the ability to identify and manage emotions to achieve self-motivation [22]. One of the seminal studies by Salovey and Mayer [23] indicated that emotional intelligence relates to the individual's competence to judge their sensations and emotions and to differentiate and use this information to control and direct others' thoughts and behavior [24]. Salovey and Mayer [23] first defined emotional intelligence as "the subset of social intelligence that involves the ability to monitor one's own and others' feelings and emotions, to discriminate among them, and to use this information to guide one's thinking and actions." Individuals with high emotional intelligence can effectively utilize their interpersonal relationships by moderating their responses, handling negative emotions, and maintaining control over their own lives $[25,26]$. Many researchers suggested that emotional intelligence consists of four dimensions: first, the appraisal and expression of emotion in oneself, which refers to an individual's competency to realize and display their deep emotions; second, the appraisal and recognition of emotion in others refers to an individual's recognition and understanding of the emotions of people around them; third, the regulation of emotion in oneself regards an individual's competency to adjust their own emotions, which can help an individual recover their emotion rapidly from psychological distress; finally, the use of emotion to facilitate performance refers to an individual's capacity to utilize their own emotions by engaging them in meaningful activities to improve their performance $[23,24,27]$.

\subsection{Cultural Adaptability}

Cultural adaptability is the additive process in which new skills and behaviors are added to or improved in an individual's original "repertoire", including the ability to utilize their positive behaviors or personality in ways appropriate in a new culture [28]. The previous studies indicated that cultural adaptability was considered as the potential for cross-cultural effectiveness and can employ their knowledge of new cultural behaviors and characteristics in different cultural circumstances [29]. Chang et al. [30] further emphasized that cultural adaptability plays a key role in interpersonal communication and enabling expatriates to survive and grow when they inhabit a new environment with unfamiliar customs, values, and assumptions.

Previous studies have demonstrated that emotional intelligence has a significant impact on and a close-relationship with cross-cultural adjustment and job performance [31], team performance [32], academic performance [33], and job satisfaction [34]. Additionally, expatriates' adaptability will be promoted if these individuals have controlled and adjusted their emotions to facilitate communication and integration with the host employees in a new environment [35]. Lin et al. [36] also illustrated that recruiters considered emotional intelligence as a critical standard to select expatriate managers, in order to decrease the uncertainty and disappointment due to cultural adaptability and boot success in international assignments. Thus, this study will promote a better understanding of emotional intelligence and its effect on other constructs. Based on the above argument, we formulate the following hypothesis:

Hypothesis 1. There is a positive relationship between emotional intelligence and cultural adaptability. 


\subsection{Cross-Cultural Competence}

Previous studies demonstrated that cross-cultural competence has been described as an individual's effectiveness in interacting successfully with people in the international environment $[4,12,19]$. Additionally, Wu and Bodigerel-Koehler [19] indicated that crosscultural competence is related to specific behavioral competencies such as rational skills, general self-efficacy, and non-ethnocentrism to work successfully with people from a different national cultural background on an overseas assignment. Moreover, there is consensus that cross-cultural competence can assist individuals in effectively managing themselves, their relationships, and their business demands in different cultural environments [37].

According to $\mathrm{Wu}$ and Bodigerel-Koehler [19], relational skills are crucial for enabling expatriates to strengthen long-term relationships, interact with host employees, and recognize conversational patterns (e.g., anecdotes, jokes, proverbs, songs, and sport). General self-efficacy is another important factor that expatriates require to handle stressors and adjust their psychological states in response to other employees [38]. Non-ethnocentrism is the other factor that involves expatriates recognizing that their traditions, culture, and patterns of behavior are no better than other dissimilar traditions, cultures, and behaviors $[19,39]$.

In a study about the relationship between emotional intelligence and cross-cultural competence with students as subjects, Guntersdorfer and Golubeva [40] demonstrated that emotional intelligence plays an important role in improving cross-cultural competence in the context of multicultural communication in schoolrooms. They emphasized that students with higher emotional intelligence are more cooperative and more likely to succeed in such multicultural collaboration environments. Additionally, in cross-cultural studies, it is also identified that cultural adaptability can facilitate employees' cultural ability to engage in impressive conservation in the new culture [14,41,42]. From the preceding discussion, the following hypotheses are proposed:

Hypothesis 2. There is a positive relationship between emotional intelligence and cross-cultural competence.

Hypothesis 3. There is a positive relationship between cultural adaptability and cross-cultural competence.

\subsection{Cross-Cultural Adjustment}

Cross-cultural adjustment is defined as the process of adjusting to a new environment or the degree of psychological adjustment experienced, including an individual's comfort and acquaintance with working and living in a culture different from their original culture [43-45]. Cross-cultural adjustment is the crucial factor in determining expatriates' success or failure on a global assignment, which is typically a challenging, complicated, and difficult process for newcomers [46]. Cross-cultural adjustment has three major dimensions: general adjustment, work adjustment, and interaction adjustment, which refers to the comfort achieved in interacting in both work and non-work situations $[3,43,47,48]$. When expatriates have high cross-cultural adjustment, they are able to pay more attention to adjusting to the new lifestyle, activities, and assignments of an organization [49].

Some previous studies demonstrated that cross-cultural adjustment is a core consequence in an expatriate's duties that would affect the development of secondary or more distal with performance [50,51]. Researchers further suggested a significant effect between emotional intelligence and cross-cultural adjustment and employee performance. Previous studies indicated that if higher emotional intelligence has been described, then crosscultural adjustment is improved [52,53]. In addition, Cai and Rodriguez [54] proposed that cultural adaptability is able to relate to actual cross-cultural adjustment for managers in multinational companies. Previous studies have also emphasized that the higher cross- 
cultural competence expatriates have, the more readily they can adjust to their new environment $[19,55]$. Therefore, the following hypotheses are suggested:

Hypothesis 4. There is a positive relationship between emotional intelligence and cross-cultural adjustment.

Hypothesis 5. There is a positive relationship between cultural adaptability and cross-cultural adjustment.

Hypothesis 6. There is a positive relationship between cross-cultural competence and cross-cultural adjustment.

\subsection{Expatriate Performance}

Previous studies demonstrated that job performance is the result of utilizing competencies, skills, attitudes, and behaviors to achieve outcomes that employees involve in tasks that are linked with and contribute to the goals and strategies of an organization [56,57]. In general, previous studies demonstrated that expatriate performance includes two important factors: contextual and task performance [58,59]. Malek and Budhwar [8] further emphasized that expatriate performance is the most crucial factor that generates behavior that contributes directly to the goals of the organization and enables an organization to compete with competitors in the host country. Since the main aim of using an expatriate on international assignments is to perform the expected tasks and to ensure all brands overseas follow the policy and strategy devised by headquarters, organizations must find justifications of the antecedents or stressors that could maximize employees' expatriate performance [8].

Previous studies established that cross-cultural adjustment is strongly correlated to expatriate performance $[8,60]$. Recently, Giorgi et al. [45] further demonstrated that individuals who have experienced more positive adjustment changes are able to get ahead of positive outcomes. Other researchers seek to elucidate the relationship between cross-cultural adjustment and expatriate performance in terms of the theory of work adjustment [61]. This theory explains that individuals and environments impose requirements on successful work relations that result from adjustment. Accordingly, well-adjusted expatriates will have better reserves of available personal resources to improve their performance on international assignments [62]. Therefore, we suggest the following hypothesis:

Hypothesis 7. There is a positive relationship between cross-cultural adjustment and expatriate performance.

\subsection{The Mediation Effects of Cross-Cultural Competence}

Earlier research has proposed that cultural adaptability is related to cross-cultural adjustment and the potential effectiveness of expatriates [54,63]. Additionally, it is also associated that cultural adaptability can foster individuals' cultural competency to integrate with new employees in cross-cultural settings [41]. In the field of international studies, it is demonstrated that cross-cultural competence has a positive relationship with cross-cultural adjustment and expatriate performance [15,19,64,65]. Wu and BodigelerKoehler [19] emphasized that the higher the cross-cultural competence expatriates have, the higher confidence they have to communicate with host employees, and the more they can regulate and control themselves in accordance with the new culture. Moreover, it is indicated that individuals will be able to accomplish their assignments better in an international environment where cross-cultural competence can aid them in improving their performance $[64,65]$. Therefore, in cross-cultural settings, the higher levels of cross-cultural competence that individuals have, the better they can adjust to the new environment, and the higher performance they can achieve $[15,19]$. 
The current study proposes that cultural adaptability enables individuals to better possess cross-cultural competence and results in better cross-cultural adjustment and expatriate performance in the new culture. In other words, cross-cultural competence may be an important process variable for understanding the influences of cultural adaptability on both cross-cultural adjustment and expatriate performance. Nevertheless, no previous studies have tried to investigate the mediating role of cross-cultural competence for the influence of cultural adaptability on cross-cultural adjustment and expatriate performance. Thus, this study intends to verify the indirect effects of the following links by using cross-cultural competence as the mediator.

Hypothesis 8a. Cross-cultural competence will mediate the influence of cultural adaptability on cross-cultural adjustment.

Hypothesis $\mathbf{8 b}$. Cross-cultural competence will mediate the influence of cultural adaptability on expatriate performance.

The proposed framework is illustrated for the present study in Figure 1.

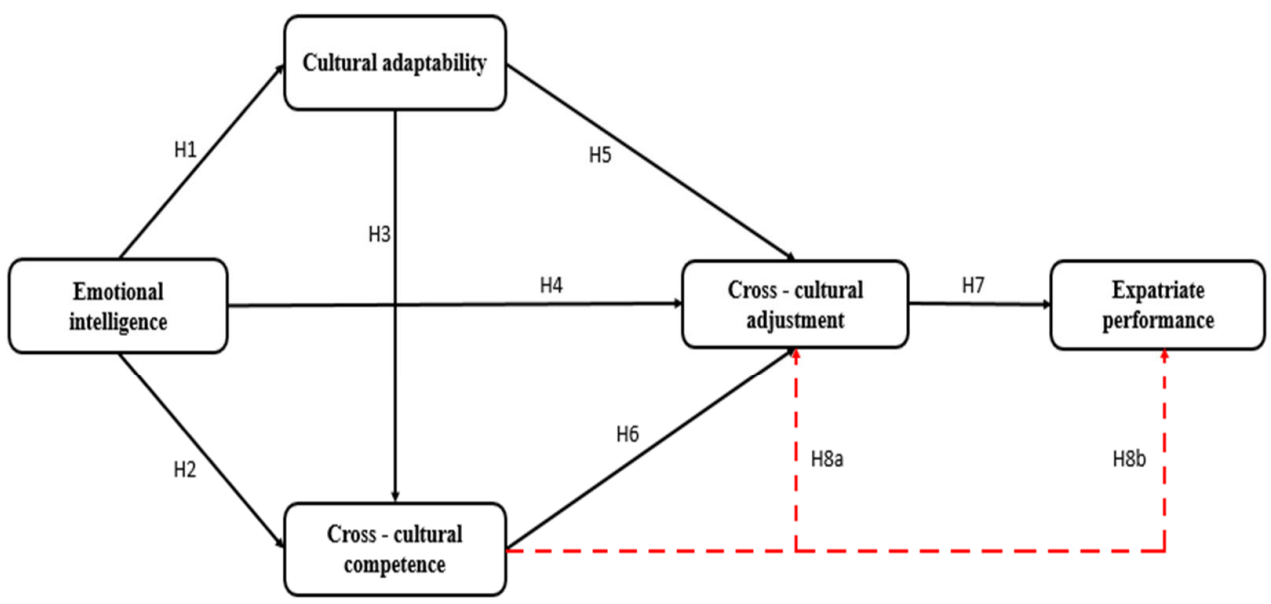

Figure 1. Proposed framework.

\section{Methodology}

\subsection{Questionnaire Design and Sampling Method}

The questionnaire items were finalized after conducting a pre-test to review and confirm that the questions are understandable and that the reliability and validity of the research constructs are ensured. Forty respondents with similar characteristics to the survey population were invited to participate in the pre-testing. These pre-test respondents were working in Taiwan, and most are friends of the members of our research team. The questionnaire items were revised based on the responses from respondents and the reliability and discriminant validity tests from the data of the pre-test.

Both online and offline surveys were conducted to reach foreign expatriates working at multinational companies in Taiwan. Before data collection, the first author wrote letters to the human resource managers of high-tech firms in Taiwan to facilitate the invitation of expatriates to participate in this study. These human resource managers then selected the expatriate employees who became samples for this study. After the human resource managers shared these expatriates' email addresses, the authors sent the questionnaire directly to the expatriates through either online or offline methods. The authors also 
joined an expatriate community site (Inter Nations Taipei) to gather additional data from expatriates. Overall, 450 survey questionnaires were delivered, although the total valid sample was 240 .

Table 1 summarizes the demographic details of the respondents. Of the 240 valid study respondents, $64.2 \%$ were male and $35.8 \%$ were female. Respondents aged 26-35 years made up a majority $(83.3 \%)$, and most of the respondents' educational backgrounds were bachelor's degrees $(77.1 \%)$. The majority of the respondents had less than three years of overseas experiences $(78.3 \%)$, followed by $3-5$ years $(20.4 \%)$ and $6-9$ years $(1.3 \%)$. Most of the respondents were supervisors in the MNCs (75.8\%) and 76.7\% of respondents had an annual income of less than 50,000 US dollars. Moreover, more than half of expatriates $(55 \%)$ were Japanese, about $20.4 \%$ of them came from North American, and $15.4 \%$ of them came from Euro.

Table 1. Demographic and descriptive information of sample.

\begin{tabular}{|c|c|c|c|}
\hline \multicolumn{2}{|c|}{ Demographic Variables } & \multirow{2}{*}{$\begin{array}{c}\text { Frequency }(n= \\
\text { 240) } \\
154\end{array}$} & \multirow{2}{*}{$\begin{array}{c}\% \\
64.2 \\
\end{array}$} \\
\hline Gender & Male & & \\
\hline & Female & 86 & 35.8 \\
\hline \multirow[t]{3}{*}{ Age } & $26-35$ & 200 & 83.3 \\
\hline & $36-45$ & 22 & 9.2 \\
\hline & $46-55$ & 18 & 7.5 \\
\hline \multirow[t]{2}{*}{ Education } & Bachelor degree & 185 & 77.1 \\
\hline & Master degree & 55 & 22.9 \\
\hline \multirow[t]{3}{*}{ Working Experience } & $<5$ years & 188 & 78.3 \\
\hline & $6-9$ years & 27 & 11.3 \\
\hline & $10-15$ years & 25 & 10.4 \\
\hline \multirow[t]{3}{*}{ Working in Abroad } & $<3$ years & 188 & 78.3 \\
\hline & $3-5$ years & 49 & 20.4 \\
\hline & $6-9$ years & 3 & 1.3 \\
\hline \multirow[t]{4}{*}{ Current Position } & Supervisor & 182 & 75.8 \\
\hline & Lower-level manager & 17 & 7.1 \\
\hline & Middle-level manager & 40 & 16.7 \\
\hline & Top manager & 1 & 0.4 \\
\hline \multirow[t]{3}{*}{ Annual Income (US dollar) } & Less than 50,000 & 184 & 76.7 \\
\hline & 50,001 to 100,000 & 41 & 17.1 \\
\hline & $>100,0001$ & 15 & 6.3 \\
\hline \multirow[t]{4}{*}{ Nationality } & North American & 49 & 20.4 \\
\hline & European & 37 & 15.4 \\
\hline & Japanese & 132 & 55.0 \\
\hline & Other countries & 22 & 9.2 \\
\hline
\end{tabular}

\subsection{Construct Measurements}

The survey questionnaire items were designed based on the review of the literature. The questionnaire items are listed as follows: Emotional intelligence was developed from Wong et al. [26]; cultural adaptability was developed from Olson and Kroger [28]; crosscultural competence was adopted from Beugelsdijk et al. [66], Harrison et al. [67], and Neuliep and McCroskey [68]; cross-cultural adjustment was developed from Befus [45] and Black and Stephens [48]; expatriate performance was adopted from Black et al. [69]. All research items are measured using a seven-point scale.

As shown in Appendix A, the results indicated that the item loadings in this research possess satisfactory value $[\geqslant 0.70],[70]$. The nine items with the standardized loadings 
below 0.70 were kept in the model since they were not significantly low and still made a theoretical contribution to the construct definition. The questionnaire items with their standardized loadings and variance inflation factor (VIF) can be found in Appendix A.

\subsection{Method}

The partial least squares path modeling algorithm and bootstrapping were adopted in this study for both the measurement model and the structural model. PLS-SEM is less restrictive judging by its normal distribution assumption, sample size restriction, and multicollinearity situation than other options [71]. According to Hair et al. [70], PLS-SEM is particularly more appropriate in the following situations: (1) when the analysis is concerned with testing a theoretical framework from a prediction perspective; (2) when the structural model is complex and includes many constructs, indicators, and/or model relationships; (3) when the research objective is to better understand increasing complexity by exploring theoretical extensions of established theories (exploratory research for theory development); and (4) when a small population restricts the sample size (e.g., businessto-business research).

\section{Results}

\subsection{Evaluation of the Measurement Model}

As demonstrated in Table 2, all Cronbach's $\alpha$ scores (ranging from 0.916 to 0.964 ) and Dijkstra-Henseler's rho (rho_A) (ranging from 0.917 to 0.967 ) are above the threshold value of 0.70 , indicating consistency and reliability. Additionally, all of the correlation coefficients among research constructs were smaller than the square roots of the average variance extracted (AVE), suggesting strong evidence of discriminant validity. Henseler et al. [72] have developed a new procedure called the heterotrait-monotrait ratio of correlations (HTMT) to examine discriminant validity. The HTMT approach has demonstrated overcomes bias and reliable performance in computing the parameters of the structural model. Teo et al. [73] suggested that HTMT should be smaller than 0.90 to show discriminant validity. Table 2 showed that the values of HTMT were much less than 0.90 , suggesting that discriminant validity has been established between two reflective variables $[70,72]$.

Table 2. Convergent and discriminant validity.

\begin{tabular}{lccccc}
\hline \multicolumn{1}{c}{ Construct } & $\mathbf{1}$ & $\mathbf{2}$ & $\mathbf{3}$ & $\mathbf{4}$ & $\mathbf{5}$ \\
\hline 1. Cultural adaptability & $\mathbf{0 . 8 9 4}$ & $0.708^{* *}$ & $0.691^{* *}$ & $0.838^{* *}$ & $0.611^{* *}$ \\
2. Cross cultural adjustment & 0.630 & $\mathbf{0 . 8 2 6}$ & $0.664^{* *}$ & $0.799^{* *}$ & $0.634^{* *}$ \\
3. Cross-cultural competence & 0.640 & 0.608 & $\mathbf{0 . 7 2 5}$ & $0.709^{* *}$ & $0.591^{* *}$ \\
4. Emotional intelligence & 0.777 & 0.737 & 0.655 & $\mathbf{0 . 8 4 7}$ & $0.626^{* *}$ \\
5. Expatriate performance & 0.519 & 0.767 & 0.624 & 0.643 & $\mathbf{0 . 8 3 2}$ \\
\hline Rho_A* & 0.917 & 0.942 & 0.956 & 0.965 & 0.928 \\
CR & 0.941 & 0.951 & 0.957 & 0.968 & 0.940 \\
Crobach's $\alpha$ & 0.916 & 0.942 & 0.953 & 0.964 & 0.926 \\
AVE & 0.799 & 0.683 & 0.526 & 0.718 & 0.692 \\
Mean & 4.553 & 4.309 & 4.364 & 4.436 & 3.892 \\
SD & 0.887 & 0.974 & 0.744 & 0.898 & 1.011 \\
\hline Notes: Above
\end{tabular}

Notes: Above the diagonal elements are the correlations between the construct values. Below the diagonal elements are the HTMT values. Square-root of AVEs are bold the numbers in the diagonals. Rho_A ${ }^{*}=$ Dijkstra-Henseler's rho; $\mathrm{CR}=$ Composite reliability; AVE = Average variance extracted; $\mathrm{SD}=$ Standard deviation. ${ }^{* *} p<0.01$.

\subsection{Structural Model and Hypothesis Testing}

According to Wetzels et al. [74], GoF=SQRT $\left(A V E * R^{2}\right)$. GoF in this study was 0.544, which is much greater than the cutoff value of 0.36 for large effect sizes. Table 3 reports 
the results of the bootstrapping tests (based on 5000 samples), including the effect sizes (coefficient $\beta$ ) and the corresponding significance of the effects ( $t$ values and $p$ values).

As shown in Table 3, the results demonstrate that emotional intelligence relates to cultural adaptability, cross-cultural competence, and cross-cultural adjustment. The path coefficients $(\beta=0.734, t=20.495, p<0.001 ; \beta=0.470, t=7.153, p<0.001 ; \beta=0.477, t=7.042$, $p<0.001$, respectively) is significant. Therefore, $\mathrm{H} 1, \mathrm{H} 2$, and $\mathrm{H} 3$ are supported, which illustrated that emotional intelligence is positively related to cultural adaptability, crosscultural competence, and cross-cultural adjustment. Additionally, the finding verifies the hypothesis of cultural adaptability to cross-cultural competence $(\beta=0.268, t=3.705, p<$ 0.001 ). Conversely, the influence of cultural adaptability on cross-cultural adjustment $(\beta=$ $0.082, t=1.186, p>0.05)$ is not supported.

Interestingly, cross-cultural competence is found significantly related to cross-cultural adjustment $(\beta=0.252, \mathrm{t}=3.421, p<0.01)$. Thus, $\mathrm{H} 6$ is supported. Result reveals expatriates with high cross-cultural adjustment display higher levels of performance $(\beta=$ $0.502, t=6.289, p<0.001$ ), which offers support for H7.

Table 3. Results for the hypothesized model using PLS.

\begin{tabular}{lccc}
\hline \multicolumn{1}{c}{ Hypothesis } & Path Coefficient & $t$-Value & Supported \\
\hline $\begin{array}{l}\text { H1. Emotional intelligence }> \\
\text { Cultural adaptability }\end{array}$ & 0.734 & $20.495^{* * *}$ & Yes \\
$\begin{array}{l}\text { H2. Emotional intelligence -> } \\
\text { Cross-cultural competence }\end{array}$ & 0.470 & $7.153^{* * *}$ & Yes \\
$\begin{array}{l}\text { H3. Emotional intelligence -> } \\
\text { Cross-cultural adjustment }\end{array}$ & 0.477 & $7.042^{* * *}$ & Yes \\
$\begin{array}{l}\text { H4. Cultural adaptability -> } \\
\text { Cross-cultural competence }\end{array}$ & 0.268 & $3.705^{* * *}$ & Yes \\
$\begin{array}{l}\text { H5. Cultural adaptability -> } \\
\text { Cross-cultural adjustment }\end{array}$ & 0.082 & 1.186 & No \\
$\begin{array}{l}\text { H6. Cross-cultural competence -> } \\
\text { Cross-cultural adjustment }\end{array}$ & 0.252 & $3.421^{* *}$ & Yes \\
$\begin{array}{l}\text { H7. Cross-cultural adjustment }-> \\
\text { Expatriate performance }\end{array}$ & 0.502 & $6.289^{* * *}$ & Yes \\
\hline
\end{tabular}

Note: ${ }^{* *} p<0.001,{ }^{* *} p<0.01$.

\subsection{The Mediation Effects of Cross-Cultural Competence}

To examine the mediating effect of cross-cultural competence, this study uses Sobel's statistical procedure test, which involves two phases. Based on MacKinnon et al. [75], the z-test was calculated using the following formula: Z-value $=a^{*} b / S Q R T\left(b^{2 *} \mathrm{SEa}^{2}+a^{2 *} \mathrm{SEb}^{2}\right)$, where $a$ is the path coefficient of the relationship between the independent and the mediator variables, $\mathrm{b}$ is the path coefficient of the relationship between the mediator and the dependent variables, $\mathrm{SE}_{\mathrm{a}}$ is the standard error of the relationship between the independent and the mediator variables, and $\mathrm{SEb}$ is the standard error of the relationship between the mediator and the dependent variables [76]. If the z-test exceeds t-value $=1.96$ with $\alpha=$ 0.05 , then the mediation effect is significant [77].

As shown in Figure 2 and Table 4, while the direct effect between cultural adaptability and cross-cultural adjustment is not significant, the indirect effect of cultural adaptability on cross-cultural adjustment is significant $(\beta=0.082, p>0.05 ; \mathrm{z}=2.531, p<0.05$, respectively), which means that the mediating effect of cross-cultural competence on the relationship between cultural adaptability and cross-cultural adjustment is confirmed. Therefore, H8a is supported, and cross-cultural competence is a full mediator between cultural adaptability and cross-cultural adjustment. Additionally, although the direct effect of cultural adaptability and expatriate performance is not significant $(\beta=-0.071, p>$ 
0.05), cultural adaptability has a positive and significant indirect effect on expatriate performance $(z=2.822, p<0.01)$, which confirms the predictions of H8b. Hence, cross-cultural competence is a full mediator between cultural adaptability and expatriate performance.

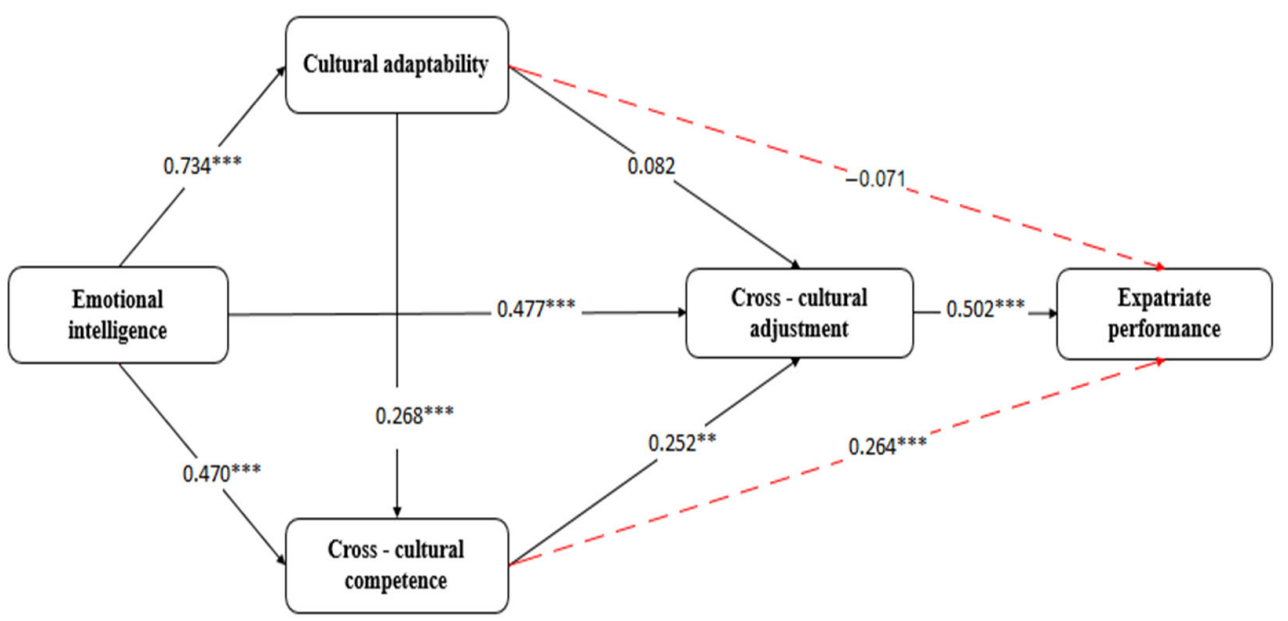

Figure 2. Structural and measurement model.

Note: ${ }^{* * *} p<0.001,{ }^{* *} p<0.01$.

Table 4. The results of the mediating effects of cross-cultural competence.

\begin{tabular}{lcccccc}
\hline \multicolumn{1}{c}{ Hypothesis } & $\mathbf{a}$ & $\mathbf{b}$ & SEa & SEb & z-Test & Supported \\
\hline $\begin{array}{l}\text { H8a. Cultural adaptability -> Cross-cultural } \\
\text { competence -> Cross-cultural adjustment }\end{array}$ & 0.268 & 0.252 & 0.072 & 0.073 & $2.531^{*}$ & Yes \\
$\begin{array}{l}\text { H8b. Cultural adaptability }>\text { Cross-cultural } \\
\text { competence }>\text { Expatriate performance }\end{array}$ & 0.268 & 0.264 & 0.072 & 0.061 & $2.822 * *$ & Yes \\
\hline
\end{tabular}

Note: ${ }^{* *} p<0.01,{ }^{*} p<0.05$.

\section{Discussions}

For many years the influence of emotional intelligence has rarely been discussed in an international assignment. Result indicates that when expatriates have high emotional intelligence, they are able to judge and generate their own and others' sensations and emotions, as well as to discriminate and use the information to control and direct behavior and action. In line with the present finding, previous studies also found that expatriates with a high level of emotional intelligence can handle their emotions when they communicate and interact with others and utilize their emotions to improve their psychological and social adaptation in a multicultural environment [25,35,36,78]. Additionally, emotional intelligence also serves as an important antecedent to cross-cultural competence. Since expatriates with high emotional intelligence can efficiently manage their responses and maintain control over their emotions [79,80]. Altinay et al. [20] further explained that individuals with higher emotional intelligence will facilitate higher cross-cultural competence in a culturally diverse setting.

The current study also illustrates that emotional intelligence directly influences crosscultural adjustment. This implies that individuals with a level high on emotional intelligence might have more ability to manage and regulate their emotions, perceive other people's emotions, master their interactions with others in a more active way, as well as utilize their emotions to improve his/her adjustment in a different multicultural environment and inhibit culture shock, relationship stress, and mental health problems [36,52]. This 
result is also consistent with the findings of previous researchers who advocated that expatriates with higher emotional intelligence are better at adjusting their emotions and interacting more effectively with their colleagues and managers [52,53].

Furthermore, our finding shows that cultural adaptability can predict an individual's cross-cultural competence. This means that individuals with higher cultural adaptability will have greater cross-cultural competence to better recognize, understand, work, and change to improve the competence inherent in a diverse cultural environment. Consequently, cross-cultural competence was determined to be the result of behavioral adaptation that facilitates individuals' ability to communicate and interact efficiently in the new environment $[18,30]$. Conversely, cultural adaptability did not have a direct effect on cross-cultural adjustment. The possible explanation for this finding is that expatriates may encounter difficulties in adjusting to the general environment, maintaining work performance levels and job standards, and satisfying supervisory responsibilities, as well as cooperating and interacting with local colleagues in the host country [41].

This study finding confirms that cross-cultural competence has positive effects on cross-cultural adjustment. Expatriates with high score cross-cultural competence are more readily able to understand, interact with, and adjust to the norms and values in the new cultural environment. Therefore, under a higher level of cross-cultural competence, expatriates will improve their cultural adjustment by undertaking their work with more energy and concentration $[15,19]$. Additionally, cross-cultural adjustment directly impacts expatriate performance, which supports the finding on the concept of adjustment by Black [81], namely that the level of the expatriate adjustment itself can determine the level of performance. Therefore, their performance will certainly be better. This finding again confirms the important role of cross-cultural adjustment, which is related to the ability and level of adjustment in a new cultural environment of individuals who are able to accomplish their assigned duties effectively [62,82].

The most remarkable outcomes of this study are the mediating mechanism of crosscultural competence on the influence of cultural adaptability on cross-cultural adjustment and expatriate performance, which are new results. The study result confirms that cultural adaptability facilitates effective adjustment for expatriates in the host country through cross-cultural competence. This finding emphasizes that when expatriates can adapt to a new environment, they will improve their cross-cultural competence, thereby enhancing them to adjust greater in a cross-cultural environment, since cultural adaptability plays a key role in interpersonal communication and enabling expatriates to survive and grow when they inhabit a new environment with unfamiliar customs, values, and assumptions [30]. However, as we discussed above, the direct effect between cultural adaptability and cross-cultural adjustment is not significant. Therefore, in the international environment, cultural adaptability can only influence cross-cultural adjustment through cross-cultural competence.

Moreover, the result primarily confirms that cross-cultural competence has operated a significant role in mediating the influences of cultural adaptability on expatriate performance. When expatriates have good communication skills and cultural knowledge, they will be confident to communicate and interact with the host employees to handle job assignments. As Chang et al. [30] have asserted, it is not only how people interact with the host culture, but also how much they are concerned about the new society and culture that have a substantial impact on their cultural competence before improving their outcome. Therefore, under a higher level of cultural adaptability, expatriates can improve their performance by undertaking their work with more energy and concentration, making them more involved in expatriate life through cross-cultural competence [55,83]. In other words, the influence of cultural adaptability on cross-cultural adjustment and expatriate performance may be voided without cross-cultural competence. 


\section{Conclusions and Contributions}

This study aims to investigate the influence of emotional intelligence and cultural adaptability on cross-cultural competence, cross-cultural adjustment, as well as the mediating role of cross-cultural competence for the influence of cultural adaptability on crosscultural adjustment and expatriate performance. The findings indicate that both emotional intelligence and cultural adaptability are essential factors for expatriates to improve their cross-cultural competence. Additionally, expatriates with a higher level of emotional intelligence and cross-cultural competence can improve their cross-cultural adjustment, which further enhances their performance. Moreover, the most notable findings of this study are that cross-cultural competence fully mediated the relationship between cultural adaptability and cross-cultural adjustment and expatriate performance. Given that research in cross-cultural competence is still in a primary stage [4], the results of this study demonstrate the potential of configurational perspectives to advance our understanding of the antecedents, characteristics, and outcomes of the nature of cross-cultural competence as well as the mediating role of cross-cultural competence in improving cross-cultural adjustment and expatriate performance in cross-cultural settings.

In our view, the analysis makes several key contributions. First, the prominent theoretical contribution of the paper is that this study's results confirm that emotional intelligence and cultural adaptability are two important antecedents of cross-cultural competence that can improve expatriate's success in a multicultural environment. The present study provides additional evidence in the research of Bartel-Radic and Giannelloni [4] and Li [5] about the antecedents that can enhance expatriates' cross-cultural competence and its outcome in the cross-cultural environment. The results are interesting and expand our understanding of the various characteristics of cross-cultural competence (including relational skills, general self-efficacy, and non-ethnocentrism) in the cross-cultural setting and thus contribute to the literature on emotional intelligence, cultural adaptability, and crosscultural competence research.

Second, this study enriches the existing literature by providing a remarkable insight into the nature of cross-cultural competence as well as its mediation role on the influence of cultural adaptability on cross-cultural adjustment and expatriate performance. Crosscultural competence should consist of the research on expatriates and their cross-cultural adjustment as a crucial explanatory factor in verifying the success of an individual in culturally diverse settings. This is an important finding because the research on cross-cultural competence has not advanced to a clearly better understanding of the concept and the feature of cross-cultural competence is highly complicated [5]. The results also answer the calls of recent studies about the need to develop a deeper understanding of what the true characteristic of cross-cultural competence really is [4,5]. These research findings are valuable since, to the best of our knowledge, there is no prior research illustrating how crosscultural competence functions on the influence of cultural adaptability on cross-cultural adjustment and expatriate performance.

Third, most of the previous studies tend to focus on the role of expatriates' cultural intelligence on cross-cultural adjustment, but few consider how emotional intelligence impacts expatriate's cross-cultural adjustment $[11,43,44,84]$. In contrast to Lii and Wong's [85] result that there is no relationship between emotional intelligence and cross-cultural adjustment, the present study reaffirms the positive and critical impact of expatriate's emotional intelligence on cross-cultural adjustment [52]. Therefore, this study expands the body of knowledge on international management by enlarging the fields in which emotional intelligence and cross-cultural adjustment have been studied.

Fourth, it goes additionally by presenting an empirical examination for how the relationship between expatriates' emotional intelligence, cultural adaptability, cross-cultural competence, cross-cultural adjustment, and expatriate performance functions. This study has provided a highly valuable milestone into the considerable role of cross-cultural competence in multinational companies. Finally, the results of this study could provide a 
valuable reference for academics as the gateway to further analysis of the role of crosscultural competence and other relevant issues.

Apart from the main findings, this study also has significant managerial implications for human resource management practices towards employees in multicultural companies. First, managers should evaluate the potential benefits of employees' emotional intelligence and cultural adaptability before dispatching them to overseas affiliates. Additionally, it is important to utilize cross-cultural competence as an index to assess expatriates' competitive advantages in overseas assignments. Second, in line with our results, expatriating firms should pay special attention to long-/short-term orientation, training programs, or assignments to enhance and nurture expatriates' emotional intelligence, cultural adaptability, and cross-cultural competence to improve their cross-cultural adjustment and productivity. Third, managers of organizations should encourage their expatriates to interact with people from different cultures, so that the misunderstandings or stress generated by experiencing an unfamiliar culture can be decreased [86]. Fourth, organizations should further consider emotional intelligence, cultural adaptability, and cross-cultural competence as essential requirements or indicators to find and evaluate employees/candidates before sending them on or hiring them for international assignments [3,53]. Finally, employees also need to be active and prepare their plans to facilitate their integration with different cultures in the new country. Being aware of suitable assignments before undertaking an international duty can help expatriates to better adapt to the emotional, psychological, and career-oriented demands of international assignments [4].

\section{Limitations and Future Studies}

Except for the contributions the research makes, the present paper also has several limitations, which should be taken into account for thoughtful generalization of the research findings and future research direction. First, the surveys were self-report based, although social desirability was considered to minimize this limitation. Therefore, future research should use sources other than self-reports, such as supervisor or spouse assessments, for the measurement of research constructs. Second, given that the sample subjects were collected through convenient sampling, our study may not be generalizable to other populations. Third, the influence of the control variable was mostly not determined. Future researchers could benefit from including different control variables. For instance, an interesting research question would be to examine the role of nationality variables in influencing the relationship among research constructs. Fourth, since the research model is still complicated with many research hypotheses, future research can develop a simpler research model and focus on the direct and indirect effect of cross-cultural competence and empirically test the feasibility of the model. Finally, this study adopted a cross-sectional survey rather than utilizing longitudinal data. Future work could extend the results of this study by adopting longitudinal research to test and improve the viability of the Ucurve and $\mathrm{W}$-curve models.

Author Contributions: Conceptualization: Y.K.L, W.Y.W, and T.C.D; Methodology: W.Y.W and T.C.D; Investigation: Y.K.L, W.Y.W, T.C.D and T.M.N.L; Software: T.C.D and T.M.N.L; Formal analysis: T.C.D and T.M.N.L; Validation: Y.K.L and T.M.N.L; Resources: Y.K.L; Writing - original draft: Y.K.L and T.C.D; Writing - review \& editing: W.Y.W, T.C.D, and T.M.N.L; Supervision: Y.K.L and W.Y.W. All authors have read and agreed to the published version of the manuscript.

Funding: This research received no external funding.

Institutional Review Board Statement: The study was conducted according to the guidelines of the Declaration of Helsinki, and approved by the Review Board of School of Business Administration, University of Economics and Business, Vietnam National University, Hanoi (Approval No. 033 and date of approval: 15th March 2021)

Informed Consent Statement: Informed consent was obtained from all subjects involved in the study. 
Conflicts of Interest: The authors declare no conflict of interest.

\section{Appendix A}

Table A1. Standardized loadings and variance inflation factor.

\begin{tabular}{|c|c|c|}
\hline Construct & $\begin{array}{c}\text { Standardized } \\
\text { Loadings }\end{array}$ & $\begin{array}{l}\text { Variance Inflation } \\
\text { Factor }\end{array}$ \\
\hline \multicolumn{3}{|l|}{ Emotional intelligence (Wong et al. 2004) } \\
\hline EIN1 When I am very down, I will try to do something to make myself feel better. & 0.891 & 4.199 \\
\hline EIN2 When I am upset, I will talk to someone who is close to me about my feeling. & 0.843 & 3.109 \\
\hline $\begin{array}{l}\text { EIN3 When my supervisor assigns a task that is not included in my job responsibility and I } \\
\text { do not have any interest in doing it, I will persuade myself that the task is not that bad and } \\
\text { perform the task. }\end{array}$ & 0.870 & 3.782 \\
\hline EIN4 When a friend comes to me because he/she is not happy, I will share his/her feeling. & 0.826 & 2.842 \\
\hline $\begin{array}{l}\text { EIN5 When someone keeps on arguing with me on some unimportant topics, I will pretend } \\
\text { to agree with his/her views and switch the discussion to other topics. }\end{array}$ & 0.840 & 3.732 \\
\hline $\begin{array}{l}\text { EIN6 My friend has a bad temper, and he/she tells me that his/her relationship with his/her } \\
\text { boy/girl friend is rough; I will point out that it is his/her friend's own fault and hope that } \\
\text { he/she will improve. }\end{array}$ & 0.863 & 4.104 \\
\hline $\begin{array}{l}\text { EIN7 Supposing I get an important award, I will tell everyone and share my happiness with } \\
\text { them. }\end{array}$ & 0.839 & 3.313 \\
\hline EIN8 When I have to do something I don't like, I try to find some interesting stuff from it. & 0.840 & 3.347 \\
\hline $\begin{array}{l}\text { EIN9 When I have a bad day, while at the same time my boss has complained about my } \\
\text { work. I will talk to a colleague or friend to release the bad feeling before starting my work. }\end{array}$ & 0.840 & 3.280 \\
\hline $\begin{array}{l}\text { EIN10 When I face problems regarding my work, I handle the problem myself because eve- } \\
\text { ryone should deal with his/her own life. }\end{array}$ & 0.829 & 2.919 \\
\hline $\begin{array}{l}\text { EIN11 I have very little chance to get the offer of a job that I like very much. I concentrate } \\
\text { my efforts on jobs that I have better chances to get offered. }\end{array}$ & 0.842 & 3.191 \\
\hline $\begin{array}{l}\text { EIN12 I have an important presentation tomorrow and I am studying hard in my room, but } \\
\text { my family has a family party. I will join the party for a while, even though I feel a little bit } \\
\text { uncomfortable. }\end{array}$ & 0.845 & 3.271 \\
\hline \multicolumn{3}{|l|}{ Cultural adaptability (Olson and Kroger 2001) } \\
\hline $\begin{array}{l}\text { CAD1 I have my own cultural, new verbal, and nonverbal communication skills to adapt to } \\
\text { another culture. }\end{array}$ & 0.894 & 3.100 \\
\hline CAD2 I believe that culture is a process. One does not have culture; one engages in culture. & 0.882 & 2.793 \\
\hline $\begin{array}{l}\text { CAD3 I am able to temporarily give up my own worldview to participate in another } \\
\text { worldview. }\end{array}$ & 0.895 & 3.289 \\
\hline $\begin{array}{l}\text { CAD4 I have two or more cultural frames of reference, and I feel positive about cultural dif- } \\
\text { ferences. }\end{array}$ & 0.905 & 3.345 \\
\hline \multicolumn{3}{|l|}{ Cross-cultural competence } \\
\hline \multicolumn{3}{|l|}{ Relational skills (Beugelsdijk et al. 2006) } \\
\hline CCC1 I always react quickly when my partner needs me. & 0.666 & 3.034 \\
\hline CCC2 I always give my partner clear and full information. & 0.698 & 2.910 \\
\hline CCC3 It is not difficult for my partners to find the right person in the organization. & 0.769 & 4.108 \\
\hline CCC4 I inform my partners in time in case of problems. & 0.631 & 2.876 \\
\hline CCC5 I systematically keep information on my most important partners. & 0.687 & 3.561 \\
\hline CCC6 I organize collective activities for and with my partner. & 0.738 & 3.573 \\
\hline $\begin{array}{l}\text { CCC7 My organization promotes informal contact between my employees and those of my } \\
\text { partner. }\end{array}$ & 0.732 & 3.394 \\
\hline \multicolumn{3}{|l|}{ General self-efficacy (Harrison et al. 1996) } \\
\hline CCC8 When I make my plans, I am certain I can make them work. & 0.737 & 3.565 \\
\hline CCC9 If I can't do a job the first time, I keep trying until I can. & 0.762 & 3.501 \\
\hline CCC10 When I have something unpleasant to do, I stick to it until I finish it. & 0.816 & 3.877 \\
\hline CCC11 When I decide to do something, I go right to work on it. & 0.801 & 3.017 \\
\hline CCC12 Failure just makes me try harder. & 0.759 & 3.140 \\
\hline
\end{tabular}




\begin{tabular}{|c|c|c|}
\hline CCC13 I am a self-reliant person. & 0.756 & 3.393 \\
\hline \multicolumn{3}{|l|}{ Non- ethnocentrism (Neuliep and McCroskey 1997) } \\
\hline $\begin{array}{l}\text { CCC14 Generally, I am comfortable interacting with a group of people from different cul- } \\
\text { tures. }\end{array}$ & 0.743 & 2.505 \\
\hline $\begin{array}{l}\text { CCC15 I like to get involved in group discussions with others who are from different cul- } \\
\text { tures. }\end{array}$ & 0.709 & 2.967 \\
\hline $\begin{array}{l}\text { CCC16 I have no fear of speaking up in a conversation with a person from a different cul- } \\
\text { ture. }\end{array}$ & 0.747 & 2.755 \\
\hline $\begin{array}{l}\text { CCC17 Ordinarily I am very calm and relaxed in conversations with a person from a differ- } \\
\text { ent culture. }\end{array}$ & 0.679 & 2.621 \\
\hline CCC18 While conversing with a person from a different culture I feel very relaxed. & 0.700 & 2.429 \\
\hline $\begin{array}{l}\text { CCC19 I face the prospect of interacting with people from different cultures with confi- } \\
\text { dence. }\end{array}$ & 0.688 & 2.759 \\
\hline CCC20 I enjoy interacting with people from different cultures. & 0.659 & 1.869 \\
\hline \multicolumn{3}{|l|}{ Cross-cultural adjustment (Befus 1988; Black and Stephens 1989) } \\
\hline CCA1 How adjusted are you to the food in Taiwan? & 0.810 & 2.512 \\
\hline CCA2 How adjusted are you to shopping in Taiwan? & 0.851 & 3.015 \\
\hline CCA3 How adjusted are you to the weather in Taiwan? & 0.823 & 2.700 \\
\hline CCA4 How adjusted are you to generally living in Taiwan? & 0.859 & 3.200 \\
\hline CCA5 How adjusted are you to the transportation system in Taiwan? & 0.860 & 3.180 \\
\hline CCA6 How adjusted are you to your job and responsibilities? & 0.844 & 3.033 \\
\hline CCA7 How adjusted are you to working with Taiwanese co-worker? & 0.835 & 2.848 \\
\hline CCA8 How adjusted are you to supervising Taiwanese subordinates? & 0.734 & 1.833 \\
\hline CCA9 How adjusted are you to working with Taiwanese outside your company? & 0.815 & 2.407 \\
\hline \multicolumn{3}{|l|}{ Expatriate performance (Black et al. 1989) } \\
\hline EPF1 My overall performance during my assignment is good. & 0.837 & 2.666 \\
\hline EPF2 I have good ability to get along with others. & 0.826 & 2.406 \\
\hline EPF3 I have capability to completing my tasks on time. & 0.796 & 2.422 \\
\hline EPF4 I have good quality of performance. & 0.842 & 2.761 \\
\hline EPF5 I have good achievement on my work goals. & 0.849 & 2.780 \\
\hline EPF6 I maintain good relationship with my local coworkers. & 0.834 & 2.639 \\
\hline EPF7 I maintain good relationship with local social environment. & 0.840 & 2.650 \\
\hline
\end{tabular}

\section{References}

1. Talent Mobility 2020. The next generation of international assignments, available online: https://www.pwc.com/gx/en/managing-tomorrows-people/future-of-work/pdf/talent-mobility-2020.pdf (accessed on 1 September 2020).

2. Ariss, A.A.; Crowley-Henry, M. Self-initiated expatriation and migration in the management literature: Present theorizations and future research directions. Career Dev. Int. 2013, 18, 78-96.

3. Lee, L.-Y.; Sukoco, B.M. The effects of cultural intelligence on expatriate performance: The moderating effects of international experience. Int. J. Hum. Resour. Manag. 2010, 21, 963-981, doi:10.1080/09585191003783397.

4. Bartel-Radic, A.; Giannelloni, J.-L. A renewed perspective on the measurement of cross-cultural competence: An approach through personality traits and cross-cultural knowledge. Eur. Manag. J. 2017, 35, 632-644, doi:10.1016/j.emj.2017.02.003.

5. Li, M. An examination of two major constructs of cross-cultural competence: Cultural intelligence and intercultural competence. Pers. Individ. Differ. 2020, 164, 110105, doi:10.1016/j.paid.2020.110105.

6. McNulty, Y.; Hutchings, K. Looking for global talent in all the right places: A critical literature review of non-traditional expatriates. Int. J. Hum. Resour. Manag. 2015, 27, 699-728, doi:10.1080/09585192.2016.1148756.

7. Zhang, Y. Expatriate development for cross-cultural adjustment. Hum. Resour. Dev. Rev. 2013, 12, 177-199, doi:10.1177/1534484312461637.

8. Hofstede, G. Cultures Consequences: International Differences in Work-Related Values; Sage: London, UK, 1980.

9. Hofstede, G. Dimensionalizing cultures: The Hofstede model in context. Online Read. Psychol. Cult. $2011,2,1$.

10. Takeuchi, R.; Yun, S.; Russel, J.E.A. Antecedents and consequences of perceived adjustment of Japanese ex-patriates in the USA. Int. J. Hum. Resour. Manag. 2002, 13, 1224-1244.

11. Malek, M.; Budhwar, P. Cultural intelligence as a predictor of expatriate adjustment and performance in Ma-laysia. J. World Bus. 2013, 48, 222-231.

12. Johnson, J.H.; Arya, B.; Mirchandani, D.A. Global integration strategies of small and medium multinationals: Evidence from Taiwan. J. World Bus. 2013, 48, 47-57, doi:10.1016/j.jwb.2012.06.006. 
13. Osman-Gani, A.M.; Rockstuhl, T. Cross-cultural training, expatriate self-efficacy, and adjustments to over-seas assignments: An empirical investigation of managers in Asia. Int. J. Intercult. Relat. 2009, 33, 277-290.

14. Qi, W.; Wang, K.T.; Pincus, A.L.; Wu, L.Z. Interpersonal problems and accul-turative stress over time among Chinese international students from mainland China and Taiwan. Asian Am. J. Psychol. 2018, 9, 237-246.

15. Wang, D.; Feng, T.; Freeman, S.; Fan, D.; Zhu, C.J. Unpacking the "skill-Cross-cultural competence" mecha-nisms: Empirical evidence from Chinese expatriate managers. Int. Bus. Rev. 2014, 23, 530-541.

16. Black, J.S.; Gregersen, H.B. Antecedents to cross-cultural adjustment for expatriates in pacificrim assignments. Hum. Relat. 1991a, 44, 497-515.

17. Black, J.S.; Gregersen, H.B. The other half of the picture: Antecedents of spouse cross-cultural adjustment. J. Int. Bus. Stud. 1991b, 22, 461-477, doi:10.1057/palgrave.jibs.8490311.

18. Johnson, J.P.; Lenartowicz, T.; Apud, S. Cross-cultural competence in international business: Toward a definition and a model. J. Int. Bus. Stud. 2006, 37, 525-543, doi:10.1057/palgrave.jibs.8400205.

19. $\mathrm{Wu}, \mathrm{Y} . \mathrm{W}$.; Bodigerel-Koehler, M. The mediating effects of cross-cultural dynamic competencies on the rela-tionship between multicultural personality and cross-cultural adjustment. Int. J. Hum. Resour. Manag. 2013, 24, 4026-4045.

20. Altinay, L.; Madanoglu, G.K.; Kromidha, E.; Nurmagambetova, A.; Madanoglu, M. Mental aspects of cultural intelligence and self-creativity of nascent entrepreneurs: The mediating role of emotionality. J. Bus. Res. 2020, doi:10.1016/j.jbusres.2020.10.048.

21. Geher, G.; Betancourt, K.; Jewell, O. The link between emotional intelligence and creativity. Imagin. Cogn. Pers. 2017, 37, 5-22, doi:10.1177/0276236617710029.

22. Dulewicz, V.; Higgs, M.; Slaski, M. Measuring emotional intelligence: Content, construct and criterion-related validity. J. Manag. Psychol. 2003, 18, 405-420, doi:10.1108/02683940310484017.

23. Salovey, P.; Mayer, J. Emotional intelligence. Imagin. Cogn. Personal. 1990, 9, 185-211.

24. Estrada, M.; Monferrer, D.; Rodríguez, A.; Moliner, M.Á. Does emotional intelligence influence academic per-formance? The role of compassion and engagement in education for sustainable development. Sustainability. 2021, $13,1721$.

25. Gebregergis, W.T.; Huang, F.; Hong, J. The impact of emotional intelligence on depression among international students studying in China: The mediating effect of acculturative stress. Int. J. Intercult. Relat. 2020, 79, 82-93, doi:10.1016/j.ijintrel.2020.08.008.

26. Wong, C.-S.; Law, K.S.; Wong, P.-M. Development and validation of a forced choice emotional intelligence measure for Chinese respondents in Hong Kong. Asia Pac. J. Manag. 2004, 21, 535-559, doi:10.1023/b:apjm.0000048717.31261.d0.

27. Giao, H.N.K.; Vuong, B.N.; Huan, D.D.; Tushar, H.; Quan, T.N. The effect of emotional intelligence on turnover intention and the moderating role of perceived organizational support: evidence from the banking industry of Vietnam. Sustain. J. Rec. 2020, 12, 1857, doi:10.3390/su12051857.

28. Olson, C.L.; Kroeger, K.R. Global competency and intercultural sensitivity. J. Stud. Int. Educ. 2001, 5, 116-137, doi:10.1177/102831530152003.

29. Bell, M.P.; Harrison, D.A. Using intra-national diversity for international assignments: A model of bicultural competence and expatriate adjustment. Hum. Resour. Manag. Rev. 1996, 6, 47-74, doi:10.1016/s1053-4822(96)90004-2.

30. Chang, W.-W.; Yuan, Y.-H.; Chuang, Y.-T. The relationship between international experience and cross-cultural adaptability. Int. J. Intercult. Relat. 2013, 37, 268-273, doi:10.1016/j.ijintrel.2012.08.002.

31. Araujo, A.V.S.; Taylor, S.N. The influence of emotional and social competencies on performance of Peruvian refinery staff. Cross Cult. Manag. 2012, 19, 19-29.

32. Miao, C.; Humphrey, R.H.; Qian, S. A meta-analysis of emotional intelligence and work attitudes. J. Occup. Organ. Psychol. 2016, 90, 177-202, doi:10.1111/joop.12167.

33. Perera, H.N.; Digiacomo, M. The relationship of trait emotional intelligence with academic performance: A meta-analytic review. Learn. Individ. Differ. 2013, 28, 20-33, doi:10.1016/j.lindif.2013.08.002.

34. Lee, H.J. How emotional intelligence relates to job satisfaction and burnout in public service jobs. Int. Rev. Adm. Sci. 2018, 84, 729-745, doi:10.1177/0020852316670489.

35. Peng, Z.R.; Wu, P.W. Measuring communication patterns and intercultural transformation of in-ternational students in crosscultural adaptation. Int. J. Intercult. Relat. 2019, 70, 78-88.

36. Lin, Y.-C.; Chen, A.S.-Y.; Song, Y.-C. Does your intelligence help to survive in a foreign jungle? The effects of cultural intelligence and emotional intelligence on cross-cultural adjustment. Int. J. Intercult. Relat. 2012, 36, 541-552, doi:10.1016/j.ijintrel.2012.03.001.

37. Caligiuri, P.; Mencin, A.; Jayne, B.; Traylor, A. Developing cross-cultural competencies through international corporate volunteerism. J. World Bus. 2019, 54, 23-24.

38. Dang, V.T.; Chou, Y. Extrinsic motivation, workplace learning, employer trust, self-efficacy and cross-cultural adjustment: An empirical study of Vietnamese laborers in Taiwan. Pers. Rev. 2020, 49, 1232-1253.

39. Young, C.A.; Haffejee, B.; Corsun, D.L. The relationship between ethnocentrism and cultural intelligence. Int. J. Intercult. Relat. 2017, 58, 31-41, doi:10.1016/j.ijintrel.2017.04.001.

40. Guntersdorfer, I.; Golubeva, I. Emotional intelligence and intercultural competence: Theoretical questions and pedagogical possibilities. Intercult. Commun. Educ. 2018, 1, 54-63, doi:10.29140/ice.v1n2.60.

41. Sony, M.; Mekoth, N. The relationship between emotional intelligence, frontline employee adaptability, job satisfaction and job performance. J. Retail. Consum. Serv. 2016, 30, 20-32, doi:10.1016/j.jretconser.2015.12.003.

42. Yamazaki, Y. Expatriate adaptation: A fit between skills and demands among Japanese expatriates in USA. Manag. Int. Rev. 2010, 50, 81-108. 
43. Hu, S.; Liu, H.; Zhang, S.; Wang, G. Proactive personality and cross-cultural adjustment: Roles of social media usage and cultural intelligence. Int. J. Intercult. Relat. 2020, 74, 42-57, doi:10.1016/j.ijintrel.2019.10.002.

44. Huff, K.C.; Song, P.; Gresch, E.B. Cultural intelligence, personality, and cross-cultural adjustment: A study of expatriates in Japan. Int. J. Intercult. Relat. 2014, 38, 151-157, doi:10.1016/j.ijintrel.2013.08.005.

45. Giorgi, G.; Lecca, L.I.; Ariza-Montes, A.; Di Massimo, C.; Campagna, M.; Finstad, G.L.; Arcangeli, G.; Mucci, N. The dark and the light side of the expatriate's cross-cultural adjustment: A novel framework including perceived organizational support, work related stress and innovation. Sustain. J. Rec. 2020, 12, 2969, doi:10.3390/su12072969.

46. Guðmundsdóttir, S. Nordic expatriates in the US: The relationship between cultural intelligence and adjustment. Int. J. Intercult. Relat. 2015, 47, 175-186, doi:10.1016/j.ijintrel.2015.05.001.

47. Befus, C.P. A multilevel treatment approach for culture shock experience by sojourners. Int. J. Intercult. Relat. 1988, 12, 381-400.

48. Black, J.S.; Stephens, G.K. The influence of the spouse on American expatriate adjustment in overseas assign-ments. J. Manag. 1989, 15, 529-544.

49. Lee, P.-Y.; Li, C.-S.J.; Wu, M.-L. The roles of cross-cultural adjustment and social capital formation in the dynamic capabilities development of multiunit organizations. Asia Pac. Manag. Rev. 2018, 23, 20-29, doi:10.1016/j.apmrv.2017.01.003.

50. Ramalu, S.S.; Chuah, F.; Rose, C.R. The effects of cultural intelligence on cross-cultural adjustment and job performance amongst expatriates in Malaysia. Int. J. Bus. Soc. Sci. 2011, 2, 59-71.

51. Ramalu, S.S.; Shamsudin, M.F.; Subramaniam, C. The mediating effect of cultural intelligence on the relation-ship between openness personality and job performance among expatriates on international assignments. Int. Bus. Manag. 2012, 6, 601-610.

52. Koveshnikov, A.; Wechtler, H.; Dejoux, C. Cross-cultural adjustment of expatriates: The role of emotional in-telligence and gender. J. World Bus. 2013, 49, 362-371.

53. Wechtler, H.; Koveshnikov, A.; Dejoux, C. Just like a fine wine? Age, emotional intelligence, and cross-cultural adjustment. Int. Bus. Rev. 2015, 24, 409-418, doi:10.1016/j.ibusrev.2014.09.002.

54. Cai, D.A.; Rodríguez, J.I. Adjusting to cultural differences: The intercultural adaptation model. Intercult. Commun. Stud. 1997, 7, 31-42.

55. Leiba-O'Sullivan, S. The Distinction between Stable and Dynamic Cross-cultural Competencies: Implications for Expatriate Trainability. J. Int. Bus. Stud. 1999, 30, 709-725, doi:10.1057/palgrave.jibs.8490835.

56. Campbell, J.P. Modeling the performance prediction problem in industrial and organizational psychology. In Handbook of Industrial and Organizational Psychology, 2nd ed.; Dunnette, M.D.; Hough, L.M.; Eds; Con-sulting Psychologists Press: Palo Alto, CA, USA. 1990, 687-732.

57. Mašková, I.; Kučera, D. Performance, achievement, and success in psychological research: towards a more transparent use of the still ambiguous terminology. Psychol. Rep. 2021, doi:10.1177/0033294121996000.

58. Bader, B.; Berg, N.; Holtbrügge, D. Expatriate performance in terrorism-endangered countries: The role of family and organizational support. Int. Bus. Rev. 2015, 24, 849-860, doi:10.1016/j.ibusrev.2015.03.005.

59. Motowidlo, S.J.; Kell, H.J. Job performance. In Handbook of Psychology: Industrial and Organizational Psychology; Schmitt, N.W., Highhouse, S., Eds.; John Wiley \& Sons, Inc.: Hoboken, NJ, USA. 2013, 12, 82-103.

60. Setti, I.; Sommovigo, V.; Argentero, P. Enhancing expatriates' assignments success: The relationships between cultural intelligence, cross-cultural adaptation and performance. Curr. Psychol. 2020, 1-21, doi:10.1007/s12144-020-00931-w.

61. Dawis, R.V. The Minnesota theory of work adjustment. In S. D. Brown \& R. W. Lent (Eds.), Career development and counseling (323). Hoboken, NJ: Wiley, 2005.

62. Lee, L.-Y.; Kartika, N. The influence of individual, family, and social capital factors on expatriate adjustment and performance: The moderating effect of psychology contract and organizational support. Expert Syst. Appl. 2014, 41, 5483-5494, doi:10.1016/j.eswa.2014.02.030.

63. Jyoti, J.; Kour, S.; Bhau, S. Assessing the impact of cultural intelligence on job performance: Role of cross-cultural adaptability. J. IMS Group. 2015, 12, 23-33.

64. Jung, D.; Paek, S.; Choe, J.Y.; Kim, J.-Y. Mediating effect of cross-cultural competency on international experiences and selfefficacy among hotel employees. Int. J. Hosp. Tour. Adm. 2019, 1-22, doi:10.1080/15256480.2019.1641456.

65. Rose, R.C.; Ramalu, S.S.; Uli, J.; Kumar, N. Expatriate performance in international assignments: the role of cultural intelligence as dynamic intercultural competency. Int. J. Bus. Manag. 2010, 5, 76, doi:10.5539/ijbm.v5n8p76.

66. Beugelsdijk, S.; Koen, C.I.; Noorderhaven, N.G. Organizational culture and relationship skills. Organ. Stud. 2006, $27,833-854$.

67. Harrison, J.; Chadwick, M.; Scales, M. The relationship between cross-cultural adjustment and the personality variables of selfefficacy and self-monitoring. Int. J. Intercult. Relat. 1996, 20, 167-188, doi:10.1016/0147-1767(95)00039-9.

68. Neuliep, J.W.; McCroskey, J.C. The development of a U.S. and generalized ethnocentrism scale. Commun. Res. Rep. 1997, 14, 385-398, doi:10.1080/08824099709388682.

69. Black, J.S.; Porter, W.,; Lyman. Managerial behaviors and job performance: A successful manager in Los Angeles may not succeed in Hong Kong. J. Int. Bus. Stud. 1991, 22, 99-113, doi; https://doi.org/10.1057/palgrave.jibs.8490294.

70. Hair, J.F.; Sarstedt, M.; Ringle, C.M.; Gudergan, S.P. Advanced Issues in Partial Least Squares Structural Equation Modeling; SAGE Publications: Thousand Oaks, CA, USA, 2017.

71. Anderson, R. E.,; Swaminathan, S. Customer satisfaction and loyalty in e-markets: A PLS path modeling approach. J. Mark. Theory Pr. 2011, 19, 2, 221-234, doi: 10.2307/23033539. 
72. Henseler, J.; Ringle, C.M.; Sarstedt, M. A new criterion for assessing discriminant validity in variance-based structural equation modeling. J. Acad. Mark. Sci. 2015, 43, 115-135, doi:10.1007/s11747-014-0403-8.

73. Teo, T.; Luan, W.S.; Sing, C.C. A cross-cultural examination of the intention to use technology between Sin-gaporean and Malaysian pre-service teachers: An application of the Technology Acceptance Model (TAM). J. Educ. Technol. Soc. 2008, 11, 265280.

74. Wetzels, M.; Odekerken-Schröder, G.; Van Oppen, C. Using PLS path modeling for assessing hierarchical con-struct models: Guidelines and empirical illustration. MIS Q. 2009, 33, 177-195.

75. MacKinnon, D.P.; Warsi, G.; Dwyer, J.H. A simulation study of mediated effect measures. Multivar. Behav. Res. 1995, 30, 41-62, doi:10.1207/s15327906mbr3001_3.

76. Iacobucci, D. Mediation analysis and categorical variables: The final frontier. J. Consum. Psychol. 2012, 22, 582-594, doi:10.1016/j.jcps.2012.03.006.

77. Sobel, M.E. Asymptotic confidence intervals for indirect effects in structural equation models. Sociol. Methodol. 1982, 13, 290, doi:10.2307/270723.

78. Deal, J.J.; Leslie, J.; Dalton, M.; Ernst, C. Cultural adaptability and leading across cultures. In Advances in Global Leadership; Elsevier B.V.: Amsterdam, The Netherlands. 2004, 149-166.

79. Gullekson, N.L.; Tucker, M.L. An examination of the relationship between emotional intelligence and intercultural growth for students studying abroad. J. Acad. Bus. Educ. 2012, 13, 162-178.

80. Yuan, B.J.C.; Hsu, W.L.; Shieh, J.H.; Li, K.P. Increasing emotional intelligence of employees: Evidence from re-search and development teams in Taiwan. Soc. Behav. Personal. Int. J. 2012, 40, 1713-1724.

81. Black, J.S. Work role transition: A study of American expatriate mangers. J. Int. Bus. Stud. 1988, 19, $277-295$.

82. Shaffer, M.A.; Reiche, S.B.; Dimitrova, M.; Lazarova, M.; Chen, S.; Westman, M.; Wurtz, O. Work-and fami-ly-role adjustment of different types of global professionals: Scale development and validation. J. Int. Bus. Stud. 2016, 47, 113-139.

83. Shaffer, M.A.; Harrison, D.A.; Gregersen, H.; Black, J.S.; Ferzandi, L.A. You can take it with you: Individual differences and expatriate effectiveness. J. Appl. Psychol. 2006, 91, 109-125, doi:10.1037/0021-9010.91.1.109.

84. Chen, A.S.-Y.; Wu, I.-H.; Bian, M.-D. The moderating effects of active and agreeable conflict management styles on cultural intelligence and cross-cultural adjustment. Int. J. Cross Cult. Manag. 2014, 14, 270-288, doi:10.1177/1470595814525064.

85. Lii, S.-Y.; Wong, S.-Y. The antecedents of overseas adjustment and commitment of expatriates. Int. J. Hum. Resour. Manag. 2008, 19, 296-313, doi:10.1080/09585190701799861.

86. Chen, A.S.-Y.; Lin, Y.-C.; Sawangpattanakul, A. The relationship between cultural intelligence and performance with the mediating effect of culture shock: A case from Philippine laborers in Taiwan. Int. J. Intercult. Relat. 2011, 35, 246-258, doi:10.1016/j.ijintrel.2010.09.005. 